\title{
IMPLEMENTATION OF LOGIC FLOW IN PLANNING AND PRODUCTION CONTROL
}

\author{
Robert Ulewicz, Dorota Jelonek, Magdalena Mazur \\ Częstochowa University of Technology, Faculty of Management, Poland
}

Corresponding author:

Magdalena Mazur

Czestochowa University of Technology

Institute of Production Engineering

Armii Krajowej 19B, 42-201 Częstochowa, Poland

phone: (+48) 34 32-50-399

e-mail:mazur.m@zim.pcz.pl

Received: 22 July 2015

Accepted: 18 February 2016

\begin{abstract}
The article presents the results of analysis, the use of continuous flow of logic at the stage of production planning and control of the company producing furniture. The concept of continuous flow tends to regulate the flow of materials in a manner that provides the shortest flow path without unnecessary activities (Muda is a Japanese word meaning waste), a constant takt and defined throughput at constant resource requirements for the so-called transfer of material through the whole process. In the study Glenday'd sieve method was used to identify the correct area, which requires the value stream mapping, and areas called excessive complexity, which do not provide added value. The use of Glenday's sieve method made it possible to identify areas in which it must be improve production capacity.
\end{abstract}

KEYWORDS

process identification, production systems, Lean manufacturing, Glenday's sieve method, structural optimization, work organization.

\section{Introduction}

The article presents the practical application of one of the Lean manufacturing tools. It presents the main assumptions of production planning and reorganized the flow of value for furniture production line. Some selection approach called later sieve method was the basis for splitting production and distribution processes into two streams. Aim of this method was to develop a new production flow and the build the possibility of their implementation in the analyzed company.

The logic of flow or continuous flow inevitably is associated with the concept of a Lean manufacturing. Work on the basis of Lean manufacturing begins with the rejection of the acceptance of waste [1]. There were seven major types of waste defined among other things, such as the inappropriate methods of manufacturing, transportation, unnecessary movements, waiting for tools and materials, overproduction $[2,3]$. The concept of a Lean manufacturing has its origins in the automotive industry [1] and since then it was widely used in the discrete manufacturing to which we can include furniture production in the analysed company. However, there are many factors that hinder the implementation of Lean manufacturing concept. It might be specific process or product properties. We may have a situation like in the case of furniture manufacturing where growth in production efficiency in connection with the extensive selection may hamper just in time production. The degree of complexity of products and their number can significantly impede the application of SMED or TPM [4]. The answer to the defined problems can be the concept of Abdulmalek et al. [5] which pointed out that in the majority of manufacturing processes there exists a point at which production can become discrete manufacturing. The introduction of the cyclic schedules (HEJUNKA) may be an effective method to synchronize discrete and indiscreet manufacturing. The key problem is the analysis and division of products into fast, medium and fast moving $[6,7]$. 


\section{Production planning}

Production planning begins at the stage of identifying customer needs and determines "what" is for him the value of the product. On the basis of this information the so called identification of value stream or sequence of all processes necessary to manufacture a product is conducted. Development of a map of processes allows to identify unnecessary processes, and develop implementation roadmap of flexible organizational structure of production.

The first function of business management is planning, which includes all levels of production organization. Planning is based on an optimal development of work time and resources. This process consists of defining the objectives, carrying out analyse of the current situation, development of the schedule and plan of activities including deciding on the implementation of the adopted strategies. The primary goal of this process is to meet the customer requirements related to the quantitative and assortment contract, as well as the date of implementation. Planning is conducted on the basis of information on material and human resources, labour consumption and material consumption of ongoing production processes and delivery dates as well as the performance of contracts, particularly the priority. The plan is also created on the basis of developed and approved projects of products, commercial and technical documentation, financial and normative requirements. The main method of planning is data analysis based on enterprise IT resources (specialized programs) $[8,9]$.

Acceptance production tasks on the basis of market analyses of a new product design results in development of an appropriate plan, including supply of the necessary factors of production, and the selection of technical process parameters. After accepting the project and selection of appropriate materials a trial batch is produced which allows to verify the intended parameters of processes and to eliminate bugs and glitches of finished product. Most important element of implementation of the plan and trial batch is the possibility of reliable calculation of production costs. The next step in the implementation of a new product is preparation of production, and therefore the purchase of necessary materials and raw materials, preparation of instrumentation together with calibration of machines, as well as possible training of personnel.

Implementation of new products is necessary because of the offered assortment, which is designed to meet the expectations of customers. Customer requirements are variable and therefore the expansion of the assortment range of the company is an integral part of sales strategy. Offering by the company wide range of products requires the development of schedule of manufacturing flow, which aims is the efficient use of resources when implementing flexible production $[10,11]$.

\section{Reduction of variation and elimination of losses}

An important element in the process of increasing the efficiency of flow is to identify loses (muda), to limit the volatility (mura) and unnecessary or unreasonable overloading people and equipment (muri) as well as systems by imposing requirements that go beyond their ability. Before working with sieve method the identification two categories of waste was carried out:

- the first category includes activities that do not increase the added value, but for some reasons, are deemed necessary,

- the second category includes activities that do not increase the added value nor are not necessary. These activities should be eliminated first.

Mura, that is volatility in every action contributes significantly to the reduction of efficiency. You should ask yourself whether maintaining the current level of variability makes economic sense. Mura applies to all resources that are wasted by the fact that it is impossible to predict quality due to the high variability of the process. It is the cost of such factors as additional tests, inspections, protective packaging, amendments, refunds or overtime due to nonstandard work. In analysed facility in order to reduce the volatility the preliminary analysis using selected instruments and statistical methods, inter alia, Pareto diagram and design of experiment (DOE) was carried out From the perspective of a Lean manufacturing, muri refers to the issue how it is planned to complete all tasks. In case the company requires employees to repeatedly performed actions that are not necessary or result in losses it shows a lack of respect for the fundamental principles of lean manufacturing, including respect for people. One of the elements eliminating muri in a furniture factory was the identification of competencies and skills of employees in terms of suitability for standard operation (green line) and for special orders of non-standard work (red line). Improper selection of employees may contribute to excessive load and stress of employees. Stressed and overloaded workers are more likely to make mistakes. Possibility of accumulation too many elements of muri in production systems and processes should be reduced. 
The more differentiation points in the manufacturing process, i.e. those in which from one group of semi-finished products is formed more than one group of semi-finished products, the more of problems will arise:

- more work and problems with planning,

- greater level of inventories of components/ materials/raw materials must be kept, taking into account the fluctuations in demand for this materials,

- more variety of facilities/equipment/tools should be possessed in order to perform certain operations differentiating semi-finished products,

- greater number of assortment items at a given stage of the manufacturing process, resulted in the need to implement retooling and consequently, rarely you can perform of semi-finished product, which in turn is associated with a decrease in the flexibility of the process and, consequently, an increase in inventories of semi-finished product and finished products,

- greater number of magazines with semi-finished products to be maintained at all points of differentiation and at the end of the stream.

The causes of excessive diversification of products can be as follows:

- product concept developed by the marketing department implemented in production without analysis,

- no optimization of orders,

- collision of goals,

- lack of comparative analysis of products in terms of similarities of the manufacturing sequence,

- constructing new sets of furniture from the beginning without the use of standard base elements.

Apart of sieve method another approach is to control the product design and technological process. In such case, it is necessary to transfer the point of differentiation as far as possible in the manufacturing process, so that you can change a part of the manufacturing process from the production of small series on batch production or mass series.

\section{Increasing of value delivered along the entire value stream}

Lean manufacturing is used in the production irrespective of whether the production involves one item a month, hundred a day or a thousand every hour. Although the woodworking shop manufacturing custom furniture may look different than the factory of mass production of bookshelves, however, in both it is used wood, it is trimmed to a specific size, sanded and lacquered, and so on. In both cases, these steps are repeated several times. The starting point to implement lean manufacturing (and to increase value) is the same: understand the customer, develop value stream map, implement $5 \mathrm{~S}$, identify the value and implement standards of work. In addition to these basics, the manufacturer may decide that he first wants to use other tools, for example, Glenday's sieve method [6].

\section{The use of Glenday's sieve method in furniture factory}

In order to minimize the costs and maximize the use of available resources in production in large batches is conducted. Such an organization extends production run (and also batch execution time) while also affecting the ability to pursue larger orders. This poses the need to adapt to changes in demand and to short-term changes in production plans. Another aspect of changes of the contract is time and interference occurring on the flow of information through individual elements of the logistics chain. Information flowing through the supply chain in the form of orders does not reflect real changes in demand in the retail market, but it contains a number of manager decisions regarding inventories. All consequences of unplanned production changes make difficult to implement standardized work, which is the basis for continuous improvement. In addition, errors during assortment changes can cause problems in terms of customer service and optimization of efficiency is achieved only within the scope of local level. In order to reduce these effects companies implement the principle of continuous flow of production based on the so-called inventories buffer tank. This approach allows to secure potential fluctuations in demand and gives time to adjust production schedules to the market situation. No need for sudden, immediate changes gives the stability and predictability of production with fixed production plan also in case of changes in demand from customer site.

Application of the principles of Glenday's sieve method aims to establish a timetable for the implementation of production of any product at each cycle of the flow, prepared to meet the needs of the market even in variable conditions. The development of an appropriate production plan requires the collection and analysis of data concerning manufactured products and their sales volumes as well as seasonality.

Presented example of organization of production using the principles of Glenday's sieve method was realized in furniture manufacturing company. The company in the initial phase of operation provided services for the individual customers on the princi- 
ple of craft production. The company has expanded its activity on their own projects and started serial production. Today the company has in its offer 12 collections of furniture made of solid wood and precious veneers. It possess a modern machines which allows for great flexibility and wide range of production. Each collection offered consists of furniture from an average of 22-25 furniture in 4 or 5 colours, which in turn creates more than 1125 bid indexes of entire range. Sorting the data according to sieve method allows to specify products which production is repetitive and which represent the bulk of sales. A fragment of data sets are shown in Table 1.

Table 1

List of furniture sales data.

\begin{tabular}{c|c|c|c|c}
\hline No & $\begin{array}{c}\text { Symbol } \\
\text { of product }\end{array}$ & $\begin{array}{c}\text { Quantitative } \\
\text { sale } \\
{[\text { unit] }}\end{array}$ & $\begin{array}{c}\text { Percentage } \\
\text { share } \\
{[\%]}\end{array}$ & $\begin{array}{c}\text { Cumulatively } \\
{[\%]}\end{array}$ \\
\hline 1. & $\mathrm{~K} 03-303 / 5$ & 1138 & 5.24 & 5.24 \\
\hline 2. & $\mathrm{~K} 03-123 / 5$ & 763 & 2.99 & 8.23 \\
\hline 3. & $\mathrm{~K} 03-327 / 5$ & 521 & 1.68 & 9.91 \\
\hline 4. & $\mathrm{~K} 03-313 / 5$ & 314 & 0.97 & 10.88 \\
\hline 5. & $\mathrm{~K} 03-243 / 2$ & 284 & 0.89 & 11.78 \\
\hline & $\ldots \ldots \ldots \ldots$ & & & \\
\hline 68. & $\mathrm{~K} 03-165 / 2$ & 102 & 0.51 & 50.24 \\
\hline & $\ldots \ldots \ldots$ & & & \\
\hline 1125 & $\mathrm{~K} 01-302 / 5$ & 0 & 0.0 & 100.00 \\
\hline
\end{tabular}

The data presented in Table 1 were used to determine the products assigned to the category of green, including products manufactured most often and in large quantities. This group includes 68 products from 3 collection representing $50 \%$ of all production monthly (on average). The final results of the distribution of manufactured products on groups are shown in Table 2.

Table 2

Results of splitting products into groups.

\begin{tabular}{c|c|c}
\hline $\begin{array}{c}\text { Sale } \\
\text { cumulatively } \\
{[\%]}\end{array}$ & $\begin{array}{c}\text { Number } \\
\text { of products }\end{array}$ & $\begin{array}{c}\text { Cods } \\
\text { of colours }\end{array}$ \\
\hline 50 & 68 & green \\
\hline 95 & 563 & yellow \\
\hline 99 & 787 & blue \\
\hline others 1 & 338 & red \\
\hline
\end{tabular}

The table demonstrates that the production of 68 types of furniture can be carried out according to a fixed strategy of volume of production (a group of "green").

In the next stage of data analysis with the aim to determine the products for which the production according to fixed production strategy would be the most effective was conducted. The average monthly volume of production standard deviation (from the average value of production) for the period of 12 months and coefficient of variation was determined. This factor is a result of ratio of standard deviation to the mean value multiplied by $100 \%$. Such ranking of assortment of produced furniture of green category according to variation coefficient have revealed that better results of application of strategy of constant volume of production will be achieved for the products of collection of "West" and "Classic" (designation K03 and K05). Among this group were tables (marked -300/), desks (marked -200/) and cabinets (marked $-100 /$ ), in the four available colours of veneer.

To implement the continuous-flow production for each of the 54 qualified products, it is necessary to set a fixed, monthly volume of production. This volume has also to guarantee the lowest cost of production, which include: costs of production, the cost of maintaining stocks of finished products, the costs of back orders and their sum defines the total cost of production. For this purpose it is necessary to use spreadsheets in order to conduct simulation of fixed volume of production for each of the qualified products.

When analysing the similarity a manufacturing of individual products after selecting products belonging to the group of green stream there is a possibility to switch selected products from the same family of products to a fixed schedule. This means that part of the range may be performed immediately after similar products from the group of green, but when the production of these smaller quantities will not interfere with the normal course of production of the green stream. This is possible if retooling of machines is not required, or when the differences in the characteristics are assigned already beyond the single line marked as green.

In order to identify the critical points of the production system visualization of process in technological terms was carried out (Fig. 1). Three main groups of furniture manufacturing processes have been determined.

The first phase of realization covers operations of formatters of the veneer including storage, interoperational transport and quality control. Technological operations include cutting out the veneer on a given dimension with a help of guillotine and bonding the layers of veneer. The second phase includes the preparation of the individual components of the product, that is: dimensional cutting out plates, veneering, drilling mounting holes according to technical drawing and varnishing. Technological operations are preceded by surface preparation and the input control. The third phase of product manufacturing 


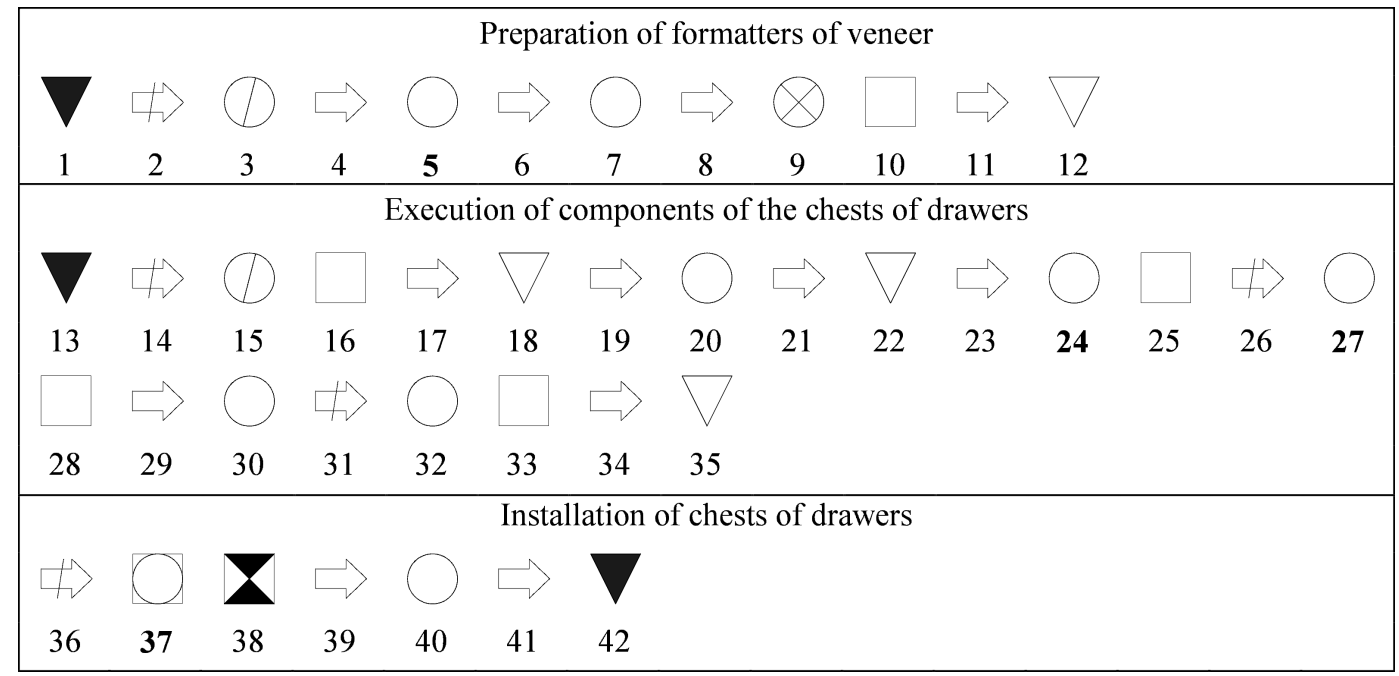

Fig. 1. Technological presentation of phases of the product realization on example of chests of drawers K03-213/05.

process is an assembly of finished components, packaging and product protection during storage and transport. Various stages of manufacturing (on the example of bureaus, Fig. 1) cover respectively: 1 storage, 2 - veneer transport on the department of veneer, 3 - sorting and preparing veneer, 4 - interoperational transport, 5 - longitudinal cut of veneer, 6 - inter-operational transport, 7 - bonding of formatters of veneer, 8 - inter-operational transport, 9 - cross cut, cutting of formatters, 10 - interoperational control, 11 - inter-operational transport, 12 - warehousing; 13 - storage of raw plates, $14-$ transport of panels for cutting department, 15 the preparation of formatters, cutting, 16 - interoperational control, 17 - inter-operational transport, 18 - storage of formatters, 19 - inter-operational transport, 20 - veneering formatters, 21 - interoperational transport, 22 - storage, 23 - interoperational transport, 24 - net formatting and veneering narrow surfaces, 25 - inter-operational control, 26 - transport to the CNC department, 27 drilling mounting holes 28 - inter-operational control, 29 - inter-operational transport 30 - surface grinding, 31 - transport to the varnishing shop department, 32 - varnishing, 33 - inter-operational control, 34 - inter-operational transport, 35 - storage of semi-finished products, 36 - transport to the assembly plant department, 37 - assembly of chests of drawers connected to the control, 38 - final tests and measurements, 39 - inter-operational transport, 40 - packaging, 41 - inter-operational transport, 42 storage.

Based on the analysis of snapshot of the work day it was found that the operations: 5, 20, 27 determine the work schedule at the stage of production of components of furniture components. In contrast operation 37 determines the schedule for an assembly of the product in the previously prepared components.

\section{Conclusions}

The best option in achieving the objectives of Glenday's sieve method is to create a separate production line on which only products from group of "green" would be manufactured and at which a fixed schedule of continuous flow of product is conducted. However, in the present case this is not possible because of the two co-production processes (Fig. 1 process 7 and 20). Therefore to achieve the maximum standardization of production, the timetable for implementation of "green" products is set on a group of shift workers. This team, depending on the changes in a given period, is specialized in the implementation of processes of fixed schedule. The aim of this approach is to improve the production capacity through the use of standardized work techniques, the organization of workplaces using $5 \mathrm{~S}$ method, whether the implementation of total productive maintenance (TPM) along with shortening the time of retooling (SMED). These elements are designed to rationalize machines retooling in relation to the size of manufactured batch and elimination of lost time due to starting production line. Preparation of constituent materials and manufacturing procedures are designed to streamlining these processes and increase their productivity index.

The main purpose of the production planning process is to produce goods in the number satisfying customer requirements in accordance with the agreed delivery date. Adopting a customer order fulfilment 
requires the involvement of company resources, and therefore it is important to properly plan taken actions which will not generate unnecessary costs.

Rational planning of production is possible using different techniques and organizational methods which will reduce activities that do not add value to products or do not bring profits. An important element of the whole project is the involvement of employees at every level of the organization. Presentation of the vision and fulfilling goals of the implementation will enable to build employees commitment to changes. Such commitment is required for implementation of continuous improvement program. Applying the philosophy of Kaizen focuses on continuous improvement of products, processes taking place in the organization. And it includes a long-term step by step improvement, every day, made by every employee, ranging from executives and ending with the rank and file employees. Analysis of the assortment using the Glenday's sieve method in a simple way allows to extract products which can be produced using a strategy of fixed volume of production. In the presented example, among 1125 types of products, 68 were distinguished that generate $50 \%$ of profits. Then, 54 groups of products were defined for which it was possible to set a fixed volume of production strategy.

Many thanks to Mr Krzysztof Krysiak and Krysiak Furniture company for their cooperation and the possibility of implementation elements of Glenday's sieve method in manufacturing processes.

\section{References}

[1] Womack J.P., Jones D.T., Roos D., The Machine that Changed the World, New York, Free Press, 1990.
[2] Ohno T., The Toyota Production System: BeyondLarge Scale Production, Portland, Productivity Press, 1988.

[3] Shingo S., A Study of the Toyota Production System, New York, Productivity Press, 1989.

[4] Van Donk D.P., Van Dam J.P., Structuring complexity in scheduling: a study in the food-processing industry, International Journal of Operations and Production Management, 16 (5), 54-63, 1996.

[5] Abdulmalek F.A., Rajgopal J., Needy K.L., A classification scheme for the process industry to guide the implementation of lean, Engineering Management Journal, 18 (2), 15-25, 2006.

[6] Glenday I., Breaking Through to Flow, Lean Enterprise Academy, Ross-on-Wye, UK, 2006.

[7] King P.L., Lean for the Process Industries Dealing with Complexity, NewYork, Productivity Press, 2009 .

[8] Pietrzak M., Jalosinski K., Paliszkiewicz J., A case study of strategic group map application used as a tool for knowledge management, Journal of Computer Information Systems, 55, 2, 68-77, 2015.

[9] Paliszkiewicz J., Knowledge management: an integrative view and empirical examination, Cybernetics and Systems: An International Journal, 38, 8, 825-836, 2007.

[10] Nowakowska-Grunt J., Modeling of innovation processes in the management of SME's enterprises activities, Advanced Materials Research, 1020, 789795, 2014.

[11] Skowron-Grabowska B., Simulation of supplies and distribution logistics systems, WMSCI 2005: 9th World Multi-Conference on Systemics, Cybernetics and Informatics, 3, 47-50, 2005. 